\title{
Redefining Dental Practice During and Post-COVID-19 era: A Review
}

\author{
Bharath Rao K. ${ }^{1}$, Saurabh Kumar², Madhumitha Natarajan ${ }^{3}$, Arul Amalan ${ }^{4}$, Runki Saran ${ }^{4}$, Pradeep S. ${ }^{5}$ \\ ${ }^{1}$ Associate Professor, Faculty of Dentistry, Melaka Manipal Medical College, Manipal Academy of Higher \\ Education, Manipal, Karnataka, India, ${ }^{2}$ Associate Professor, Department of Pedodontics, Manipal College of \\ Dental Sciences, Manipal Academy of Higher Education, Manipal, Karnataka, India, ${ }^{3}$ Associate Professor, \\ Manipal College of Dental Sciences, Manipal Academy of Higher Education, Manipal, Karnataka, India, ${ }^{4}$ Senior \\ Lecturer, Faculty of Dentistry, Melaka Manipal Medical College, Manipal Academy of Higher Education, \\ Manipal, Karnataka, India, ${ }^{5}$ Professor \& Head, Manipal College of Dental Sciences, Manipal Academy of Higher \\ Education, Manipal, Karnataka, India
}

\begin{abstract}
The spread of the COVID-19 pandemic has led to widespread concerns internationally and among the members of the public health community including dental health professionals. The dental health care professionals are at higher than usual risk due to the proximity to the patient's face, direct contact with the body fluids such as saliva and blood. The objective of this article is to provide an overview of the symptoms, modes of transmission of the COVID-19 infection, triaging of the dental patients, specific recommendations for the management of the dental patient, infection control modalities with an emphasis on dental specialties, global outlook on the pandemic by dentists, and implications on the patients and dentists. A literature search was performed and articles about the symptoms and modes of transmission of the COVID-19 infection, management of COVID-19 diffusion in dental practice were retrieved. The articles were then reviewed and infection control measures for various dental specialties as well as patient management strategies were also outlined in the results. The dental team has to implement measures to provide care and treatment to the patient as well as prevent the spread of the infection.
\end{abstract}

Keywords: COVID-19, Dental Practice, Cross Infections, Patient Management, Risk stratification, Dental Triaging.

\section{Introduction}

The prevailing COVID-19 pandemic in the world is caused by a virus named SARS-CoV-2 (severe acute respiratory syndrome coronavirus 2). SARS-

\section{Corresponding Author:}

\section{Dr. Saurabh Kumar}

Associate Professor, Department of Pedodontics, Manipal College of Dental Sciences, Manipal Academy of Higher Education, Manipal, Karnataka, India e-mail: saurabh.kumar@manipal.edu

Telephone : +91-820-2922063;

Mobile : +919916316486
Cov-2 belongs to a large family of viruses called the Coronaviruses (CoVs). ${ }^{[1]}$ The China health authority informed the World Health Organization of multiple cases of pneumonia of unknown etiology in the Wuhan province on December 31st, 2019. Most of the patients lived or worked around the Huanan local seafood wholesale market. ${ }^{[2]}$ On January $7^{\text {th }}, 2020$, the WHO abbreviated the new pathogen discovered from the throat swab of one of the patients as 2019-nCoV. ${ }^{[3]}$ The Coronavirus Study Group renamed the pathogen as severe acute respiratory syndrome coronavirus 2 (SARS-CoV-2). There was no evidence of human to human transmission in the first two weeks of detection of the disease, and it was considered to be a normal flu consisting of acute respiratory problems with a common cold. A severe outbreak of the virus happened in China 
in the third week of January 2020, followed by spread throughout the globe ${ }^{[4]}$. As on September 3, 2020, the total number of laboratory-confirmed cases in the world are $26,182,709$, of which $18,446,689$ have recovered, and the number of deaths is $867,362 \cdot{ }^{[5]}$ An extensive search was carried out on COVID-19 and dental health professions on the internet to obtain literature. Gaps and areas of wealth in the literature were identified

Symptoms of Covid-19: A patient infected with COVID-19 may present with mild, moderate, or severe illness. Patients suffering from mild illness present with upper respiratory tract infection, mild fever, dry cough, sore throat, nasal congestion, headache, muscle pain, or malaise. Ageusia or loss of taste and/or anosmia or loss of smell, diarrhea, and vomiting have also been observed. Cough and shortness of breath without signs of severe pneumonia are seen during the phase of the moderate illness. Fever with severe dyspnoea, respiratory distress, tachypnoea ( $>30$ breaths/min), and hypoxia $\left(\mathrm{SpO}_{2}<\right.$ $90 \%$ on room air) is seen in severe illness. Children present with mild cyanosis, too. ${ }^{[6]}$

Modes of spread and risk associated with COVID-19 in dental clinics: COVID-19 can be transmitted from one person to another directly through respiratory droplets, with recent studies suggesting that transmission may occur via contact and could be fomite borne. ${ }^{[7],[8]}$ The asymptomatic incubation period for infected individuals has been reported to be approximately $1-14$ days, but asymptomatic individuals could spread the virus after 24 days. ${ }^{[9],[10],[11]}$ The presence of the live virus in the saliva of the infected was demonstrated by To et al. ${ }^{[7]}$ The virus binds to the human ACE -2(angiotensin-converting enzyme 2) receptors, which are present in high concentrations in the salivary glands. ${ }^{[12],[13]}$

The dental care setting carries an increased risk of transmitting infection due to the procedures carried out that involve close facial communication with the patient, multiple, often long exposure to body fluids such as blood, saliva, sweat, etc. as well as sharp instruments and armamentarium. Transmission of the virus may be due to direct inhalation of microbe, which is airborne and could remain suspended for long duration in the air; due to direct contact with patient materials ${ }^{[14]}$, contact with the conjunctival, nasal, or oralmucosa with droplets and aerosols containing the virus. Cough froman infected individual may propel the virus a short distance in the form of droplets. ${ }^{[15],[16]}$ Contact with contaminated instruments and surfaces can also lead to the spread of the infection. ${ }^{[17]}$

However, among the modes mentioned above, droplet and aerosol transmission of the virus are of utmost concern in the dental clinic as it is tough to avoid generating a massive quantity of aerosol as well as droplet containing the patient's saliva and blood during dental practice. The dental instruments such as hand pieces use gas to drive the turbine to rotate at high speeds and work with running water and generate aerosols and droplets mixed with the patient's saliva and blood which could stay airborne for a while and further settle on surfaces or enter the respiratory tract. ${ }^{[15]}$ Besides, dental professionals and other patients have likely contact of conjunctival, nasal, or oral mucosa with droplets and aerosols containing microorganisms generated from an infected individual and propelled a short distance by coughing and talking without a mask. Effective infection control strategies are needed to prevent the spread of 2019-nCoV through these contact routines ${ }^{[18],[19]}$.

Cough or sneeze by an infected person can render the virus and infect individuals within a radius of approximately 2 meters, thus forming the basis for the social distancing measures among the community to decrease the spread.

Inanimate objects located close to an infected individual or touched by him/her could be a source of spread $^{[20],[21] .}$ Handwashing and disinfection play a key role in stopping the spread of this disease ${ }^{[22] .}$

Tele dentistry and messaging services during the COVID-19 pandemic:

- Tele dentistry can be a practical approach during the COVID-19 pandemic to decrease the number of patients visiting the dental clinic and thus limiting the visits to emergency and urgent dental care.

- WhatsApp Messenger, owned by Facebook Inc., California, is a text messaging service that can be used for communication between the dentist and the patient. Members of the dental health team should be appropriately taught to use these internetbased communication tools with an assessment of indications and contra indications. Virtual assistance in the form of photographs, short video clips, or video calls can be of great use for communication between the patient and dentist to evaluate the need of the patient to visit the dental clinic. ${ }^{[23],[24],[25]}$ 
Triaging of Dental Patients: The patients visiting the dental clinic can be segregated based on the criteria mentioned in Table 1.

Table 1: Critera for segregating the dental patients in dental clinic

\begin{tabular}{|c|c|c|}
\hline Priority & Procedures & Management \\
\hline Emergency & $\begin{array}{l}\text { - Deep head and neck infections with airway obstruction } \\
\text { - Malignant tumors which involve reconstructive procedures } \\
\text { - Open Fractures } \\
\text { - Periapical abscess/abscess with swelling that might lead to space infections } \\
\text { - Severe hemorrhage/bleeding } \\
\text { - Swelling due to preactivated orthodontic appliance }\end{array}$ & $\begin{array}{l}\text { Appropriate treatment to be } \\
\text { provided }\end{array}$ \\
\hline Priority & $\begin{array}{l}\text { - Tempromandibular joint pathology causing pain } \\
\text { - Benign slow-growing tumors and cysts } \\
\text { - Cleft lip and palate surgery } \\
\text { - Closed fractures } \\
\text { - Root canal treatment/Pulpectomy/Pulpotomy } \\
\text { - Extraction of third molar/any other tooth with no periapical infection }\end{array}$ & $\begin{array}{l}\text { Conservative management } \\
\text { depending on the condition } \\
\text { until COVID } 19 \text { situation } \\
\text { improves. }\end{array}$ \\
\hline $\begin{array}{l}\text { Postpone (until } \\
\text { the COVID-19 } \\
\text { pandemic has } \\
\text { settled) }\end{array}$ & $\begin{array}{l}\text { - Orthognathic surgery } \\
\text { - Cosmetic procedures } \\
\text { - Orthodontic treatment } \\
\text { - Restorations(caries not very deep) } \\
\text { - Scaling and root planning } \\
\text { - Crown and bridge procedures } \\
\text { - Abscess } \\
\text { - Ill-fitting prosthesis } \\
\text { - Dental implant }\end{array}$ & $\begin{array}{l}\text { Deferred until the } \\
\text { COVID-19 situation is } \\
\text { entirely under control }\end{array}$ \\
\hline
\end{tabular}

Management of a patient with symptoms of COVID-19: If a patient has symptoms of COVID-19, then the patient needs to be categorized as a high-risk patient and may be managed as stated in figure 1 .

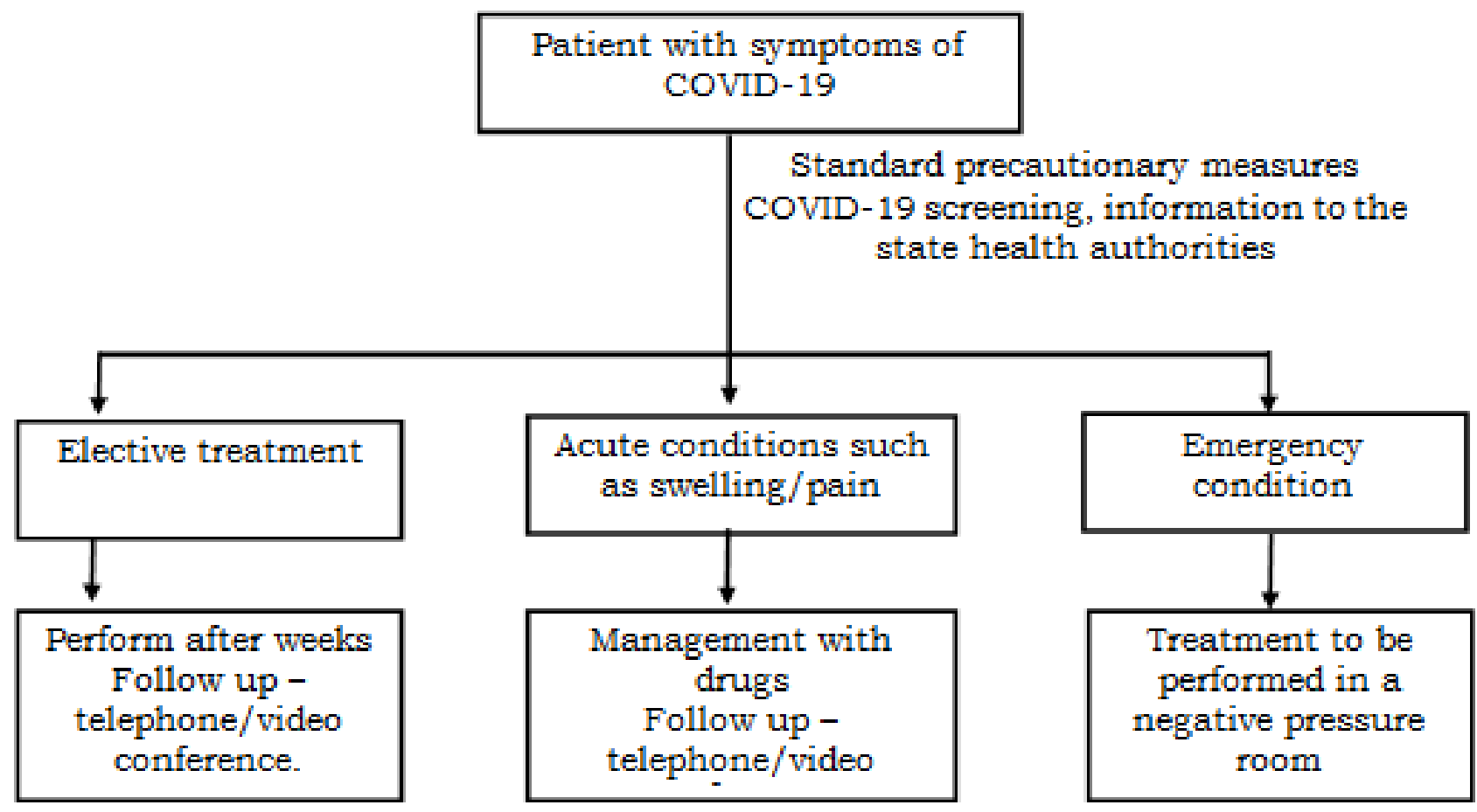

Figure 1: Management of a patient with symptoms of COVID-19 
There is no standard protocol for the various specialities of dentistry as well as general dentistry on the approach to management of a patient during and post the Covid-19 pandemic. This discussion lays down the guidelines for the management of a dental patient with prevention of nosocomial infection as well as guidelines of individual dental speciailities.

a. Management of a dental patient and prevention of hospital-acquired/nosocomial infection

- Elective procedures to be deferred and only urgent/ emergency procedures to be performed

- Standard, contact, and airborne precautions to be followed by the dentists, which include the use of personal protective equipment(PPE)as well as following hand hygiene practices ${ }^{[26]}$

- Use of mouth rinse before the procedure: SARSCoVis known to highly susceptible topovidone mouth rinse. ${ }^{[27]}$ Rinsing can be advised before the procedure, and $0.2 \%$ povidone-iodine may be used. This could help in the reduction of the virus in the saliva. ${ }^{[28],[29]}$

- Some of the dental instruments used in the clinic, such as mouth mirrors and syringes, should be disposable or single-use, which prevents prevent cross-infection.

- Extraoral radiographs $\{\mathrm{OPG} \& \mathrm{CBCT}$ (Cone beamcomputed tomography) $\}$ should be recommended to avoid gagging or initiation of the cough reflex, which is frequent during intraoral imaging. If an IOPA or any other intraoral imaging procedure is mandatory, then the sensorsshould be double barriered. ${ }^{[30]}$

- Rubber dam minimizes splatter generation.

- The use of ultrasonic armamentarium, as well as high-speedhandpieces and 3-way syringes, should be reduced to decrease the generation of contaminatedaerosols.

- Negative-pressure treatment rooms or ff2 and well ventilated operating rooms (AIIRs) to be usedto treat a suspected orlab confirmed COVID-19 positive patient rather than in a routine dental clinic setting. ${ }^{[31]}$

- Disinfection of the inanimate surfaces with chemicals as the SARS CoV-2 virus could survive and stay viable in aerosols for 2 to 3 daysat room temperature on inanimate objects or surfaces. ${ }^{[31]}$ b. Patient management by certain individual dental specialties

\section{Oral and maxillofacial surgery:}

\section{Outpatient:}

- Minimum patients to be entertained as no elective surgery to be performed

- Consultation on the phone/video call to be held before face to face meeting with documentation of the telehealth procedures

- Minimum number of patients to be present in the waiting room; contact time to be shortened

- Risk assessment of the patient to assess the possibility of having contracted the infection to be done by recording the body temperature and evaluation of the respiratory symptoms

- Evaluation of the contact and clinical history contact with a patient with respiratory problems and fever in the previous 2 to 3 weeks.

\section{Inpatient Care:}

- All the inpatients to undergo a swab test for COVID-19 as a routine.

- New patients to be separated from the rest of the patients until a negative result is obtained.

- PPE to be used by the medical staffas a mandate. ${ }^{[26]}$

- Mask and gloves to be used in case of asymptomatic patients to avoid droplet infection

\section{Operating Room:}

- Test for COVID-19 to be performed before shifting the patient into the operating room

- FFP2(Filter face piece) respirator without valve and a gown to be worn by the patient

- FFP2 respirator with a valve and a gown and gloves to used by the staff

- Negative pressure to be established in the operating room

- PPE to be worn by every staff member with a watertight sterile gown over it

- Face shield to be worn by the operating doctor and the assisting team member

- Members of the surgical team to be outside the room during intubation and extubation 
- Extraoral approach to be used if possible

- Use of osteotome to be considered wherever possible

- Minimum aerosol formation to be a priority

- Use of electric cautery to be avoided and if used should be with a smoke evacuation machine

- The operating room to be cleaned and disinfected 15 minutes after the patient has left the room $^{[32],[33]}$.

\section{Endodontic Practice:}

- Dilution of sodium hypochlorite to a concentration of $1 \%$ to extend the supply with no compromise on the quality of the treatment

- Rubber dam usage to minimize generation of splatter. Care must to taken to place the rubber dam to cover the nose for an advantage to decrease the spread of the infection. ${ }^{[26]}$
Pediatric Dental Practice: Riccardo Castagnoli et al. ${ }^{[34]}$ studied COVID1-9 positive pediatric patients in China over three months and concluded that children acquired the viral infection from their family members but presented with less severe symptoms than in adults. The prognosis was also better with recovery in 1 to 2 weeks after the onset of the disease.

- Preventive dental behaviors should be promoted

\section{Orthodontic Practice:}

- Postpone routine orthodontic appointment as per guidelines of the single Nations

- Follow up of patients experiencing discomfort or problems concerning the orthodontic appliance they are using. ${ }^{[23]}$ Table II below shows the followup procedure for dental pateints.

Table II: Orthodontic followup for dental patients

\begin{tabular}{|c|c|c|}
\hline \multicolumn{3}{|l|}{ Removable appliance } \\
\hline Functional appliance & Broken/does not fit & Send a photograph to the orthodontist and discontinue use after consultation \\
\hline Aligner & Broken/lost & $\begin{array}{l}\text { Continue wearing } \\
\text { Wear the previous one and consult the orthodontist }\end{array}$ \\
\hline Retainer & Broken/lost & Consult the orthodontist to help buy hot customizable ones online \\
\hline \multicolumn{3}{|l|}{ Fixed appliances } \\
\hline \multirow[t]{4}{*}{ Straightwire appliance } & Loosened brackets & $\begin{array}{l}\text { Send a photograph to the orthodontist } \\
\text { Remove with tweezers }\end{array}$ \\
\hline & Poking wire & $\begin{array}{l}\text { Send a photograph to the orthodontist. } \\
\text { Cut with the help of a disinfected cutter. }\end{array}$ \\
\hline & Poking ligature wire & $\begin{array}{l}\text { Send a photograph to the orthodontist. } \\
\text { Use was and then } n \text { eraser to push it backward. }\end{array}$ \\
\hline & $\begin{array}{l}\text { An abscess around the } \\
\text { molar band }\end{array}$ & $\begin{array}{l}\text { Send a photograph to the orthodontist. } \\
\text { Antibiotics and analgesics }\end{array}$ \\
\hline $\begin{array}{l}\text { Patient activated } \\
\text { appliances }\end{array}$ & $\begin{array}{l}\text { Headgear } \\
\text { Facemask } \\
\text { Lip bumper } \\
\text { Palatal expanders }\end{array}$ & Discontinue use \\
\hline \multirow[t]{2}{*}{ Preactivated appliances } & $\begin{array}{l}\text { Forsus } \\
\text { Distal jet appliance }\end{array}$ & Send a photograph to the orthodontist once in 2 to 3 weeks. \\
\hline & & In case of pain/swelling/severe discomfort - visit an emergency dental clinic. \\
\hline
\end{tabular}

\section{Discussion}

Dental practice: Global outlook during the COVID-19 outbreak: The dental clinic setting increases the risk of cross-contamination and infection between the dental health care worker and the patient. Stern and effective infection control procedures are to be followed by the dental practitioners and hospitals in the countries affected/potentially affected by COVID-19. 
After the outbreak of the disease in China in late 2019 , routine dental treatment was suspended in January 2020. After three months, the situation is limping back to normalcy ${ }^{[35],[36]}$. Countries closely linked to China, which include Hong Kong, Taiwan, and Singapore, imposed travel restrictions, quarantines, social distancing measures, self-isolation, and heightened hygiene to decrease the arrival of new cases among the community and prevent silent community spread of the pandemic. Routine dental care was closed down just as in China.

The UK NHS's was of the view that dental practitioners should continue to provide routine dental care for patients who are asymptomatic with no contact history. The general dental practitioners were not comfortable with this advice. They felt that they were morally obliged to reduce routine dental care to decrease the spread of COVID-19 among patients and further into the community. However, the financial consequences of the self-employed dentists were also understandably of concern $^{[37]}$. The British Dental Association (BDA) has informed the $\mathrm{BBC}$ (British Broadcasting Corporation) that dentists in the united kingdom have been receiving multiple calls from patients who are believed to be in real agonizing pain, with no option of sending them anywhere. As per the British Dental Association, there are a large number of patients who are going untreated; it also says that some of the untreated conditions such as abscesses could lead to facial space infections and thus end up being life-threatening. Patients have been asked to call their local practitioners and seek prescriptions on the phone and obtain them from the pharmacy in case of serious symptoms. Numerous patients are not able to receive emergency appointments as practices are not allowed to see the patient face to face.

Dentistry has been termed as the riskiest of professions in relation to COVID-19 by The New York Times ${ }^{[38]}$. The American Dental Association (ADA) has urged the US Department of Health and Human Services to federally recognize licensed dentists to administer point of service COVID-19 tests to test a patient before the procedure henceforth decrease the risk of exposure to the entire dental team

The ADA has made recommendations for the reimbursement for costs incurred due to the procurement and use of Personal protective equipment(PPE) as well as payments for temporary procedures. ${ }^{[40]}$ Teledentistry facilities are being made available to the dentists in certain states of USA. ${ }^{[41]}$
The dental clinics across the Indian subcontinent have been asked to suspend all non-essential procedures since March 31 ${ }^{\text {st }}$, 2020. The Indian Dental Association(IDA), in its bulletin released on March 17th, 2020, titled "Be prepared ... but don't panic" directed the dentists in India to concentrate on emergency dental care and to make a well-informed decision about the patient and their practice. ${ }^{[42]}$

COVID-19: Implications faced by patients, dentists, and dental businesses: North American Dental Group ("NADG"), a leading U.S. Dental Service Organization, has reported that a considerable number of Americans have raised significant concerns about seeking dental treatment during the current COVID-19 pandemic. Seventy-one percent of the patients were uncomfortable visiting the dental clinic and wanted to postpone an elective procedure. Only 42 percent of the Americans were confident that their dentist was prepared to prevent the spread of the COVID pandemic.

Dental treatment is expensive and not entirely covered by insurance. A patient to whom oral health has always been of utmost importance is likely to return to the clinic and also bear the costs. However, there will be many who would postpone their visit to the dental beyond the lockdown due to fear or due to economic effects due to job losses, salary cuts, etc. Patients residing in countries who have the lockdown are finding it tough to reach a dentist even in case of emergencies such as broken teeth as a result of biting onto something hard ${ }^{[43]}$.

The overhead expenses of the dentists in developing and undeveloped countries is expected to rise as the dentist has to procure PPEs. There has been an acute shortage of as well as unclear guidance on PPEs in the United Kingdom. ${ }^{[44]}$

There have been severe financial problems faced by dental offices, health care operators, and hospitals as well as insurance companies. As dental treatments are limited only to emergency treatments, the management of patients has become expensive. One of the very adverse impacts of the dental practices being shut down is on the salaries of the dental staff. Unemployment insurance in developed nations could partially cover their requirements. ${ }^{[45],[46]}$

\section{Conclusion}

Dentistry: The way ahead

- Change in the approach by the dentist, patient as 
well as the government.

- Use of teledentistry to minimize the footfall at the dental clinic.

- Only emergency procedures to be performed.

- Changes in the infrastructure of outpatient and inpatient units, as well as the operating room.

- Adequate supply and use of personal protective equipment by the dental health care team.

- Permission to allow the dentists to take nasal and throat swabs of the patients for the coronavirus.

- Low-interest loans for dental practices.

\section{Declarations:}

\section{Ethics Approval and Consent to Participate:}

- Not required

\section{Consent for publication:}

- All the others duly give consent for the publication of the article

\section{Availability of data and material:}

- Please contact author for data requests."

\section{Competing interest:}

- The authors declare no conflict of interest, financial or otherwise.

\section{Funding:}

- Not a funded project

\section{References}

1. WHO. Novel-Coronavirus-2019@www.who.int.

2. $\mathrm{Lu} \mathrm{H}$, Stratton $\mathrm{CW}$, Tang Y. Outbreak of pneumonia of unknown etiology in Wuhan, China: The mystery and the miracle. J Med Virol. 2020 Apr;92(4):401-2.

3. Hui DS, I Azhar E, Madani TA, Ntoumi F, Kock R, Dar O, et al. The continuing 2019-nCoV epidemic threat of novel coronaviruses to global health The latest 2019 novel coronavirus outbreak in Wuhan, China. Int J Infect Dis. 2020 Feb;91:2646.

4. Gorbalenya AE, Baker SC, Baric RS, Groot RJ De, Gulyaeva AA, Haagmans BL, et al. The species and its viruses - a statement of the Coronavirus Study Group. Biorxiv (Cold Spring Harb Lab. 2020;1-15.

5. www.worldometers.info. 2020.
6. Wu Z, McGoogan JM. Characteristics of and Important Lessons From the Coronavirus Disease 2019 (COVID-19) Outbreak in China. JAMA. 2020 Apr;323(13):1239.

7. To KK-W, Tsang OT-Y, Yip CC-Y, Chan K-H, Wu T-C, Chan JM-C, et al. Consistent Detection of 2019 Novel Coronavirus in Saliva. Clin Infect Dis. $2020 \mathrm{Feb}$;

8. Rodríguez-Morales AJ, MacGregor K, Kanagarajah S, Patel D, Schlagenhauf P. Going global - Travel and the 2019 novel coronavirus. Travel Med Infect Dis. 2020 Jan;33:101578.

9. Huang C, Wang Y, Li X, Ren L, Zhao J, Hu Y, et al. Clinical features of patients infected with 2019 novel coronavirus in Wuhan, China. Lancet. 2020;395(10223):497-506.

10. Wei-jie Guan, Ph.D., Zheng-yi Ni, M.D., Yu Hu, M.D., Wen-hua Liang, PD, Chun-quan Ou, MSc., Jian-xing He, M.D., Lei Liu, M.D., Hong Shan MD, Chun-liang Lei, M.D., David S.C. Hui, M.D., Bin Du, M.D., Lan-juan Li MD, Guang Zeng, MSc., Kwok-Yung Yuen, Ph.D., Ru-chong Chen, M.D. CT, M.D., Tao Wang, M.D., Ping-yan Chen, M.D., Jie Xiang, M.D., Shi-yue Li, M.D. J, Wang, M.D., Zi-jing Liang, M.D., Yi-xiang Peng, M.D., Li Wei, M.D. YL, et al. Clinical characteristics of 2019 novel coronavirus infection in China. medRxiv. 2020;4(1):1-7.

11. Backer JA, Klinkenberg D, Wallinga J. Incubation period of 2019 novel coronavirus (2019-nCoV) infections among travellers from Wuhan, China, 20-28 January 2020. Eurosurveillance. 2020 Feb;25(5).

12. Hoffmann M, Kleine-Weber H, Schroeder S, Krüger N, Herrler T, Erichsen S, et al. SARS-CoV-2 Cell Entry Depends on ACE2 and TMPRSS2 and Is Blocked by a Clinically Proven Protease Inhibitor. Cell. 2020 Apr;181(2):271-280.e8.

13. Sabino-Silva R, Jardim ACG, Siqueira WL. Coronavirus COVID-19 impacts to dentistry and potential salivary diagnosis. Clin Oral Investig. 2020 Apr;24(4):1619-21.

14. Chen J. Pathogenicity and transmissibility of 2019-nCoV-A quick overview and comparison with other emerging viruses. Microbes Infect. 2020 Mar;22(2):69-71.

15. Cleveland JL, Gray SK, Harte JA, Robison VA, Moorman AC, Gooch BF. Transmission of blood- 
borne pathogens in US dental health care settings. J Am Dent Assoc. 2016 Sep;147(9):729-38.

16. HARREL SK, MOLINARI J. Aerosols and splatter in dentistry. J Am Dent Assoc. 2004 Apr;135(4):429-37.

17. Liu L, Wei Q, Alvarez X, Wang H, Du Y, Zhu H, et al. Epithelial Cells Lining Salivary Gland Ducts Are Early Target Cells of Severe Acute Respiratory Syndrome Coronavirus Infection in the Upper Respiratory Tracts of Rhesus Macaques. J Virol. 2011 Apr;85(8):4025-30.

18. Kampf G, Todt D, Pfaender S, Steinmann E. Persistence of coronaviruses on inanimate surfaces and their inactivation with biocidal agents. J Hosp Infect. 2020 Mar;104(3):246-51.

19. Otter JA, Donskey C, Yezli S, Douthwaite S, Goldenberg SD, Weber DJ. Transmission of SARS and MERS coronaviruses and influenza virus in healthcare settings: the possible role of dry surface contamination. J Hosp Infect. 2016 Mar;92(3):23550 .

20. Centro para el control y prevención de Enfermedades. Index@ @ww.Cdc.Gov. 2012 West Nile virus update. 2012.

21. Peng X, Xu X, Li Y, Cheng L, Zhou X, Ren B. Transmission routes of 2019-nCoV and controls in dental practice. Int J Oral Sci. 2020;12(1):1-6.

22. Kwok YLA, Gralton J, McLaws M-L. Face touching: A frequent habit that has implications for hand hygiene. Am J Infect Control. 2015 Feb;43(2):112-4.

23. Caprioglio A, Pizzetti GB, Zecca PA, Fastuca R, Maino G, Nanda R. Management of orthodontic emergencies during 2019-NCOV. Prog Orthod. 2020 Dec;21(1): 10.

24. Laura Veneroni, Andrea Ferrari, Stefania Acerra, Maura Massimino CAC. Considerazioni sull'uso di WhatsApp nella comunicazione e relazione medicopaziente. Recenti Prog Med. 2015;106(7):331-6.

25. Mars M, Scott RE. WhatsApp in Clinical Practice: A Literature Review. Stud Health Technol Inform. 2016;231:82-90.

26. Infection-control-recommendations @ www.cdc. gov.

27. Eggers M, Koburger-Janssen T, Eickmann M, Zorn J. In Vitro Bactericidal and Virucidal Efficacy of Povidone-Iodine Gargle/Mouthwash Against
Respiratory and Oral Tract Pathogens. Infect Dis Ther. 2018 Jun;7(2):249-59.

28. Kariwa H, Fujii N, Takashima I. Inactivation of SARS coronavirus by means of povidone-iodine, physical conditions, and chemical reagents. Jpn J Vet Res. 2004 Nov;52(3):105-12.

29. Visit https://www.epa.gov/pesticide-registration/ list-n-disinfectants-use-against- sars-cov-2 to find the current list of products that meet EPA's criteria for use against SARS-CoV-2, the cause of COVID-19. :20460.

30. HOKETT SD, HONEY JR, RUIZ F, BAISDEN MK, HOEN MM. Assessing the effectiveness of direct digital radiography barrier sheaths and finger cots. J Am Dent Assoc. 200Apr;131(4):463-7.

31. Ather A, Patel B, Ruparel NB, Diogenes A, Hargreaves KM. Coronavirus Disease 19 (COVID-19): Implications for Clinical Dental Care. J Endod. 2020 May;46(5):584-95.

32. Zimmermann M, Nkenke E. Approaches to the management of patients in oral and maxillofacial surgery during COVID-19 pandemic. J CranioMaxillofacial Surg. 2020 Apr;

33. Guan W, Ni Z, Hu Y, Liang W, Ou C, He J, et al. Clinical Characteristics of Coronavirus Disease 2019 in China. N Engl J Med. 2020 Apr;382(18):1708-20.

34. Castagnoli R, Votto M, Licari A, Ilaria B, Raffaele B, Stefano P, Francesca R, Fausto Baldanti, Gian Luigi Marseglia JAMA Pediatr. 2020 Apr 22. doi:10.1001/jamapediatrics.2020.1467.

35. Meng L, Hua F, Bian Z. Coronavirus Disease 2019 (COVID-19): Emerging and Future Challenges for Dental and Oral Medicine. J Dent Res [Internet]. 2020 May 12;99(5):481-7. Available from: http://journals.sagepub.com/ doi/10.1177/0022034520914246

36. Coulthard P. Dentistry and coronavirus (COVID-19) - moral decision-making. Br Dent J. 2020;228(7):503-5.

37. health-52197788@www.bbc.com.

38. coronavirus-worker-risk@www.nytimes.com.

39. ada-urges-hhs-to-federally-recognize-licenseddentists-to-administer-point-of-service-covid-19test @www.ada.org.

40. en@ success.ada.org. 
41. new-teledentistry-reimbursement-available-tomedi-cal-dental-providers-during-covid-19-crisis @www.cda.org.

42. www.dental-tribune.com.

43. broken-tooth-pain-covid-19-restrictions-1@www. cbc.ca.
44. www.dentistry.co.uk.

45. www.zerodonto.com.

46. what-is-the-covidified-future-for-dentists @www. dentistryiq.com. 